\title{
Association of cigarette smoking with a past history and incidence of herpes zoster in the general Japanese population: the SHEZ Study
}

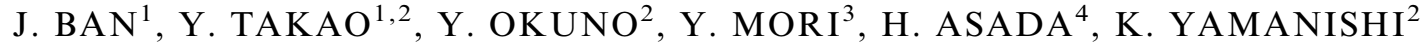 \\ AND H. ISO ${ }^{1 *}$ \\ ${ }^{1}$ Public Health, Department of Social Medicine, Osaka University Graduate School of Medicine, Osaka Japan \\ ${ }^{2}$ The Research Foundation for Microbial Diseases of Osaka University, Kagawa, Japan \\ ${ }^{3}$ Division of Clinical Virology, Kobe University Graduate School of Medicine, Kobe, Japan \\ ${ }^{4}$ Nara Medical University School of Medicine, Nara Japan
}

Received 2 October 2016; Accepted 6 December 2016; first published online 16 January 2017

\section{SUMMARY}

Few studies have examined the impact of cigarette smoking on the risk for herpes zoster. The Shozu Herpes Zoster (SHEZ) Study is a community-based prospective cohort study over 3 years in Japan aiming to clarify the incidence and predictive and immunological factors for herpes zoster. We investigated the associations of smoking status with past history and incidence of herpes zoster. A total of 12351 participants provided valid information on smoking status and past history of herpes zoster at baseline survey. Smoking status was classified into three categories (current, former, never smoker), and if currently smoking, the number of cigarettes consumed per day was recorded. The participants were under the active surveillance for first-ever incident herpes zoster for 3 years. We used a logistic regression model for the cross-sectional study on the association between smoking status and past history of herpes zoster, and a Cox proportional hazards regression model for the cohort study on the association with risk of incidence. The multivariable adjusted odd ratios $(95 \% \mathrm{CI})$ of past history of herpes zoster for current $v s$. never smokers were $0.67(0.54-0.80)$ for total subjects, $0.72(0.56-0.93)$ for men and $0.65(0.44-0.96)$ for women. The multivariable adjusted hazard ratios $(95 \% \mathrm{CI})$ of incident herpes zoster for current $v s$. never smokers were $0.52(0.33-0.81)$ for total subjects, $0.49(0 \cdot 29-0.83)$ for men and $0.52(0 \cdot 19-1.39)$ for women. Smoking status was inversely associated with the prevalence and incidence of herpes zoster in the general population of men and women aged $\geqslant 50$ years.

Key words: Herpes zoster, Japanese adults, prospective cohort study, smoking status.

\section{INTRODUCTION}

Herpes zoster is a painful vesicular rash caused by reactivation of latent varicella zoster virus (VZV) dominant in dorsal root ganglia after its primary

\footnotetext{
* Author for correspondence: H. Iso, MD, Public Health, Department of Social Medicine, Osaka University Graduate School of Medicine, 2-2 Yamadaoka, Suita-city, Osaka 565-0871, Japan

(Email: iso@pbhel.med.osaka-u.ac.jp)
}

infection [1, 2]. Reactivation occurs when cellular immunity against the virus falls below the levels that would have maintained the latent status [3]. Elderly people, in particular, are likely to develop herpes zoster through reduced levels of the immune system along with ageing [4], immunosuppressive disorders like HIV [5] and cancer [6]. By contrast, people who had contact with varicella cases, e.g. physicians and primary school teachers, were less likely to develop herpes zoster because of boosted VZV-specific 
cell-mediated immunity [7, 8]. Furthermore, psychological stress [9, 10], mechanical trauma [11] and diets [12], such as low fruit intake, have been proposed as factors for developing herpes zoster probably through a reduced immune system [3].

Several previous studies $[3,9]$ noted an inverse association between smoking and risk of herpes zoster. However, those studies investigated smoking as a confounding variable, but not as a prediction for herpes zoster in a systematic way.

In this paper, we investigated the association of smoking status with a past history and incidence of herpes zoster in the Shozu Herpes Zoster (SHEZ) Study.

\section{METHODS}

The SHEZ Study is a 3-year community-based prospective cohort study in Shozu County, Kagawa Prefecture, which aimed to clarify the incidence and predictive and immunological factors for herpes zoster. The detailed methods of this study have been described elsewhere [13].

\section{Subjects}

The target population was Japanese residents aged $\geqslant 50$ years in Shozu County (Shodoshima and Teshima Islands in Kagawa prefecture). Of 19058 residents (8424 men, 10634 women) aged $\geqslant 50$ years on 1 October 2008, a total of 12522 persons (5587 men, 6935 women) participated in the SHEZ study (overall participation rate $65 \cdot 7 \%$ ).

\section{Baseline information collection at enrolment}

The baseline survey was carried out between December 2008 and November 2009. The past history of herpes zoster was obtained at the registration interview by research physicians. The subject was asked whether and when he/she had received a diagnosis of herpes zoster from a physician. Information regarding family history of herpes zoster, underlying diseases (high blood pressure, hyperlipidaemia, diabetes mellitus, connective tissue disease, cancer, leukemia or other diseases), lifestyle behaviours, social and psychological factors were elicited by trained interviewers using a structured questionnaire. Smoking status was classified into three categories; current, former or never smoker. For current smokers, the number of cigarettes consumed per day was recorded and was categorized into 1-9, 10-19,
20-29 and $\geqslant 30$ cigarettes per day. A former smoker was defined as a person who had stopped smoking at baseline. Lifestyle behaviours included walking, exercise, sleep and diet (consumption of fruit, vegetables, fish, meat, eggs, miso soup, soybeans, milk and alcohol) were also enquired. Social and psychological factors included talking with others, opportunities for laughing, self-rated health, sleep satisfaction, perceived mental stress, a sense of purpose in life and social support. We excluded 163 subjects (78 men, 85 women) who did not provide information on smoking status and past history of herpes zoster from the analyses.

\section{Surveys after enrolment}

To confirm the development of herpes zoster, a telephone survey was conducted with each subject once every 4 weeks. Subjects who presented with symptoms suggestive of herpes zoster and did not consult a doctor at the time were invited to the medical institutions and were examined by physicians for diagnosis.

\section{Statistical analysis}

In the cross-sectional analysis, logistic regression analysis was used to estimate the odds ratios (ORs) and their $95 \%$ confidence intervals ( $95 \%$ CIs) for the association between smoking status and past history of herpes zoster after adjustment for selected confounding variables, i.e. age, sex, family history of herpes zoster and present history of underlying diseases.

In the cohort analysis, incidence of herpes zoster was expressed per 1000 person-years, and a Cox proportional hazards regression model was used to estimate hazard ratios (HRs) and their 95\% CIs for the association between smoking status and incident herpes zoster. We adjusted for selected confounding variables, i.e. age, sex, family history of herpes zoster, present history of underlying diseases and psychological factors such as perceived mental stress and well-being. The data were analysed with SAS software for Windows v. 9.1 (SAS Institute Japan Ltd, Japan). All statistical tests were two-tailed and $P<0.05$ was regarded as significant.

\section{Standard protocol approvals, registrations, and patient consent}

The SHEZ Study was conducted in accordance with the Ethical Guidelines for Epidemiological Research and the Ethical Guideline for Clinical studies after 
Table 1. Characteristics of participants at baseline, the SHES Study

\begin{tabular}{|c|c|c|c|}
\hline & Men & Women & $P$ for difference \\
\hline No. of total subjects for the cross-sectional analysis & 5509 & 6850 & \\
\hline Age, years, mean \pm s.D. & $67 \cdot 2 \pm 10 \cdot 1$ & $68 \cdot 9 \pm 10 \cdot 8$ & $<0 \cdot 001$ \\
\hline \multicolumn{4}{|l|}{ Age, years, $n(\%)$} \\
\hline $50-59$ & $1488(27 \cdot 0)$ & $1671(24 \cdot 4)$ & \multirow{4}{*}{$<0 \cdot 001$} \\
\hline $60-69$ & $1820(33 \cdot 0)$ & $1962(28 \cdot 7)$ & \\
\hline $70-79$ & $1440(26 \cdot 1)$ & $1929(28 \cdot 2)$ & \\
\hline$\geqslant 80$ & $761(13 \cdot 8)$ & $1282(18 \cdot 7)$ & \\
\hline \multicolumn{4}{|l|}{ Smoking status, $n(\%)$} \\
\hline Never & $1039(18 \cdot 9)$ & $6406(93 \cdot 5)$ & \multirow{7}{*}{$<0 \cdot 001$} \\
\hline Former & $2564(46 \cdot 5)$ & $198(2 \cdot 9)$ & \\
\hline Current & $1906(34 \cdot 6)$ & $246(3 \cdot 6)$ & \\
\hline $1-9$ cigarettes per day & $237(4 \cdot 3)$ & $94(1 \cdot 4)$ & \\
\hline $10-19$ & $651(11 \cdot 8)$ & $94(1 \cdot 4)$ & \\
\hline $20-29$ & $642(11 \cdot 7)$ & $42(0 \cdot 6)$ & \\
\hline$\geqslant 30$ & $376(6 \cdot 8)$ & $16(0 \cdot 2)$ & \\
\hline Past history of herpes zoster, $n(\%)$ & $660(12 \cdot 0)$ & $1310(19 \cdot 1)$ & \multirow[t]{4}{*}{$<0.001$} \\
\hline No. of subjects without past history of herpes zoster for the cohort analysis & 4849 & 5540 & \\
\hline Age, years, mean \pm s.D. & $66 \cdot 8 \pm 10 \cdot 1$ & $68 \cdot 5 \pm 10 \cdot 9$ & \\
\hline \multicolumn{3}{|l|}{ Age, years, $n(\%)$} & \\
\hline $50-59$ & $1363(28 \cdot 1)$ & $1456(26 \cdot 3)$ & \multirow{4}{*}{$<0.001$} \\
\hline $60-69$ & $1621(33 \cdot 4)$ & $1560(28 \cdot 2)$ & \\
\hline $70-79$ & $1232(25 \cdot 4)$ & $1511(27 \cdot 3)$ & \\
\hline$\geqslant 80$ & $633(13 \cdot 1)$ & $1013(18 \cdot 3)$ & \\
\hline Incidence of herpes zoster, $n(\%)$ & $119(2 \cdot 5)$ & $216(3 \cdot 9)$ & $<0 \cdot 001$ \\
\hline \multicolumn{4}{|l|}{ Smoking status, $n(\%)$} \\
\hline Never & $916(18 \cdot 9)$ & $5158(93 \cdot 1)$ & \multirow{7}{*}{$<0 \cdot 001$} \\
\hline Former & $2178(44 \cdot 9)$ & $166(3 \cdot 0)$ & \\
\hline Current & $1755(36 \cdot 2)$ & $216(3 \cdot 9)$ & \\
\hline 1-9 cigarettes per day & $217(4 \cdot 5)$ & $80(1 \cdot 4)$ & \\
\hline $10-19$ & $605(12 \cdot 5)$ & $81(1 \cdot 5)$ & \\
\hline $20-29$ & $591(12 \cdot 2)$ & $40(0 \cdot 7)$ & \\
\hline$\geqslant 30$ & $342(7 \cdot 1)$ & $15(0 \cdot 3)$ & \\
\hline
\end{tabular}

obtaining informed consent from subjects [13] and was approved by the Ethics Committee of the Research Foundation for Biomedical Diseases of Osaka University, the National Institute of Biomedical Innovation and Nara Medical University.

\section{RESULTS}

Table 1 shows the characteristics of the participants at baseline. Men were slightly younger than women. Smoking status differed substantially between the sexes; $36 \cdot 2 \%$ of men and $3.9 \%$ of women were current smokers, while $18.9 \%$ of men and $93.1 \%$ of women were never smokers. The prevalence of past history of herpes zoster was $12 \cdot 0 \%$ in men and $19 \cdot 1 \%$ in women. Similar trends were observed when participants with past history of herpes zoster were excluded for the cohort analysis.
Table 2 presents age- and sex-adjusted and multivariable adjusted ORs (95\% CIs) of prevalent herpes zoster according to smoking status in total subjects, men and women. Compared to never smokers as the reference group, the age- and sex-adjusted ORs for current $v s$. never smokers were $0.64(0.52-0.78)$ for total subjects, $0.71(0.55-0.92)$ for men, and 0.63 $(0 \cdot 42-0 \cdot 92)$ for women. The corresponding multivariable adjusted ORs $(95 \%$ CIs) were $0.67(0 \cdot 54-0 \cdot 80)$, $0.72(0.56-0.93)$ and $0.65(0.44-0.96)$, respectively. The age- and sex-adjusted ORs for former $v$ s. never smokers were $1.15(0.96-1.36)$ for total subjects, 1.30 $(1 \cdot 05-1 \cdot 62)$ for men and $0.80(0.54-1 \cdot 17)$ for women. The corresponding multivariable adjusted ORs $(95 \%$ CIs) were $1.13(0.95-1.34), 1.26(1.01-1.57)$ and 0.81 $(0 \cdot 55-1 \cdot 19)$, respectively. There was no dose-response relationship between the number of cigarettes consumed per day and prevalence herpes zoster. 
Table 2. Odds ratios (95\% CIs) of past history of herpes zoster according to smoking status: the cross-sectional analysis

\begin{tabular}{|c|c|c|c|c|c|}
\hline & \multirow[b]{2}{*}{ No. of participants } & \multirow[b]{2}{*}{ No. of prevalent cases $(\%)$} & \multicolumn{2}{|l|}{ Odds ratio $(95 \% \mathrm{CI})$} & \multirow[b]{2}{*}{$* P$ value } \\
\hline & & & Age- and sex-adjusted & Multivariable adjusted* & \\
\hline \multicolumn{6}{|l|}{ Total subjects } \\
\hline Never smoker & 7445 & $1371(18 \cdot 4)$ & 1.00 & 1.00 & \\
\hline Former smoker & 2762 & $418(15 \cdot 1)$ & $1 \cdot 15(0 \cdot 96-1 \cdot 36)$ & $1 \cdot 13(0 \cdot 95-1 \cdot 34)$ & $0 \cdot 182$ \\
\hline Current smoker & 2152 & $181(8 \cdot 4)$ & $0 \cdot 64(0 \cdot 52-0 \cdot 78)$ & $0 \cdot 67(0 \cdot 54-0 \cdot 80)$ & $<0 \cdot 001$ \\
\hline \multicolumn{6}{|c|}{ No. of cigarettes smoked per day among current smokers } \\
\hline $1-9$ & 331 & $34(10 \cdot 3)$ & $0.67(0 \cdot 46-0.97)$ & $0.67(0 \cdot 46-0.97)$ & 0.033 \\
\hline $10-19$ & 745 & $59(7 \cdot 9)$ & $0.59(0 \cdot 44-0 \cdot 79)$ & $0 \cdot 61(0 \cdot 45-0 \cdot 82)$ & $0 \cdot 001$ \\
\hline $20-29$ & 684 & $53(7 \cdot 8)$ & $0 \cdot 62(0 \cdot 45-0 \cdot 85)$ & $0.65(0 \cdot 47-0 \cdot 89)$ & $0 \cdot 007$ \\
\hline$\geqslant 30$ & 392 & $35(8 \cdot 9)$ & $0 \cdot 75(0 \cdot 52-1 \cdot 10)$ & $0 \cdot 77(0 \cdot 53-1 \cdot 13)$ & $0 \cdot 186$ \\
\hline \multicolumn{6}{|l|}{ Men } \\
\hline Never smoker & 1039 & $123(11 \cdot 8)$ & $1 \cdot 00$ & $1 \cdot 00$ & \\
\hline Former smoker & 2564 & $386(15 \cdot 1)$ & $1 \cdot 30(1 \cdot 05-1 \cdot 62)$ & $1 \cdot 26(1 \cdot 01-1 \cdot 57)$ & $0 \cdot 039$ \\
\hline Current smoker & 1906 & $151(7 \cdot 9)$ & $0.71(0.55-0.92)$ & $0.72(0.56-0.93)$ & $0 \cdot 012$ \\
\hline \multicolumn{6}{|c|}{ No. of cigarettes smoked per day among current smokers } \\
\hline $1-9$ & 237 & $20(8 \cdot 4)$ & $0 \cdot 68(0 \cdot 41-1 \cdot 11)$ & $0.66(0 \cdot 40-1.09)$ & $0 \cdot 103$ \\
\hline $10-19$ & 651 & $46(7 \cdot 1)$ & $0.62(0.43-0.88)$ & $0.63(0.44-0.90)$ & $0 \cdot 011$ \\
\hline $20-29$ & 642 & $51(7 \cdot 9)$ & $0 \cdot 74(0.52-1 \cdot 05)$ & $0.75(0.53-1.07)$ & $0 \cdot 109$ \\
\hline$\geqslant 30$ & 376 & $34(9 \cdot 0)$ & $0.88(0.59-1.32)$ & $0.89(0.59-1.34)$ & 0.585 \\
\hline \multicolumn{6}{|l|}{ Women } \\
\hline Never smoker & 6406 & $1248(19 \cdot 5)$ & 1.00 & 1.00 & \\
\hline Former smoker & 198 & $32(16 \cdot 2)$ & $0 \cdot 80(0 \cdot 54-1 \cdot 17)$ & $0 \cdot 81(0 \cdot 55-1 \cdot 19)$ & 0.283 \\
\hline Current smoker & 246 & $30(12 \cdot 2)$ & $0.63(0 \cdot 42-0.92)$ & $0.65(0 \cdot 44-0.96)$ & $0 \cdot 029$ \\
\hline \multicolumn{6}{|c|}{ No. of cigarettes smoked per day among current smokers } \\
\hline $1-19$ & 188 & $27(14 \cdot 4)$ & $0 \cdot 74(0 \cdot 49-1 \cdot 12)$ & $0 \cdot 76(0 \cdot 50-1 \cdot 15)$ & $0 \cdot 199$ \\
\hline$\geqslant 20$ & 58 & $3(5 \cdot 2)$ & $0.26(0.08-0.83)$ & $0.28(0.09-0.89)$ & 0.031 \\
\hline
\end{tabular}

* Adjusted for age, sex, family history and underlying diseases.

Table 3 shows age- and sex-adjusted and multivariable adjusted HRs for incident herpes zoster according to smoking status in persons without past history of herpes zoster. Compared to never smokers as the reference group, the age- and sex-adjusted HRs (95\% CIs) for current vs. never smokers were $0 \cdot 51$ $(0.32-0.79)$ for total subjects, $0.49(0.29-0.83)$ for men and $0.51(0 \cdot 19-1 \cdot 36)$ for women. The corresponding multivariable adjusted HRs (95\% CIs) were $0.52(0.33-0.81), 0.49(0.29-0.83)$ and 0.52 $(0 \cdot 19-1 \cdot 39)$, respectively.

\section{DISCUSSION}

In our epidemiological study of the general population, current smoking was associated with lower risk of prevalent and incident herpes zoster, compared to never smoking for total subjects, men and women, separately. There was, however, no dose-response relationship of the number of cigarettes smoked per day with risk of prevalent and incident herpes. For men, former smoking was associated with higher prevalence of herpes zoster, but was not associated with risk of incident herpes zoster.

A prospective cohort study of 4162 American men and women aged $\geqslant 65$ years ( $46 \%$ for whites, $54 \%$ for blacks) reported the HRs of incident herpes zoster according to smoking status [14]. The participants were interviewed at baseline and the in-person interviews were repeated at 3-year intervals for 6 years. The HR $(95 \% \mathrm{CI})$ of incident herpes zoster for current smoker $v$ s. current nonsmoker was $0.47(0.25-0.89)$ after adjustment for age, race, sex, marital status, education, presence of a confidant, perceived adequacy of social support, the Social Network Scale, the Social Interaction Scale, chronic diseases, basic activities of daily living (ADLs), instrumental ADLs, depression, self-rated health and hospitalization. Our corresponding HR $(95 \% \mathrm{CI})$ was $0.58(0.35-$ 0.97), which implies a similar result. 
Table 3. Hazard ratios (95\% CIs) of incident herpes zoster according to smoking status: the cohort analysis

\begin{tabular}{|c|c|c|c|c|c|c|}
\hline & \multirow[b]{2}{*}{ Person-years } & \multirow{2}{*}{$\begin{array}{l}\text { No. of } \\
\text { incident } \\
\text { cases }\end{array}$} & \multirow{2}{*}{$\begin{array}{l}\text { Incidence rate } \\
\text { per } 1000 \\
\text { person-years }\end{array}$} & \multicolumn{2}{|c|}{ Hazard ratio $(95 \% \mathrm{CI})$} & \multirow[b]{2}{*}{$\begin{array}{l}P \\
\text { value }\end{array}$} \\
\hline & & & & $\begin{array}{l}\text { Age- and } \\
\text { sex-adjusted }\end{array}$ & $\begin{array}{l}\text { Multivariable- } \\
\text { adjusted* }\end{array}$ & \\
\hline \multicolumn{7}{|c|}{ Total subjects without past history of herpes zoster } \\
\hline Never smoker & 17971 & 236 & $13 \cdot 1$ & $1 \cdot 00$ & $1 \cdot 00$ & \\
\hline Former smoker & 6854 & 68 & $9 \cdot 92$ & $0 \cdot 88(0 \cdot 60-1 \cdot 28)$ & $0 \cdot 87(0 \cdot 59-1 \cdot 27)$ & $0 \cdot 456$ \\
\hline Current smoker & 5886 & 31 & $5 \cdot 27$ & $0 \cdot 51(0 \cdot 32-0 \cdot 79)$ & $0 \cdot 52(0 \cdot 33-0 \cdot 81)$ & $0 \cdot 004$ \\
\hline $1-19$ & 2930 & 15 & $5 \cdot 12$ & $0.47(0 \cdot 27-0 \cdot 83)$ & $0 \cdot 48(0 \cdot 27-0 \cdot 85)$ & $0 \cdot 012$ \\
\hline$\geqslant 20$ & 2956 & 16 & $5 \cdot 41$ & $0 \cdot 55(0 \cdot 31-0.98)$ & $0 \cdot 56(0 \cdot 31-1 \cdot 00)$ & $0 \cdot 051$ \\
\hline \multicolumn{7}{|l|}{ Men } \\
\hline Never smoker & 2696 & 31 & $11 \cdot 5$ & $1 \cdot 00$ & $1 \cdot 00$ & \\
\hline Former smoker & 6376 & 61 & $9 \cdot 57$ & $0 \cdot 82(0 \cdot 53-1 \cdot 26)$ & $0 \cdot 82(0 \cdot 53-1 \cdot 26)$ & $0 \cdot 360$ \\
\hline Current smoker & 5247 & 27 & $5 \cdot 15$ & $0.49(0.29-0.83)$ & $0.49(0 \cdot 29-0.83)$ & $0 \cdot 008$ \\
\hline $1-19$ & 2451 & 12 & $4 \cdot 90$ & $0.45(0.23-0.87)$ & $0.45(0.23-0.87)$ & $0 \cdot 018$ \\
\hline$\geqslant 20$ & 2795 & 15 & $5 \cdot 37$ & $0.53(0 \cdot 28-1 \cdot 00)$ & $0 \cdot 54(0 \cdot 29-1 \cdot 01)$ & $0 \cdot 053$ \\
\hline \multicolumn{7}{|l|}{ Women } \\
\hline Never smoker & 15276 & 205 & $13 \cdot 4$ & $1 \cdot 00$ & $1 \cdot 00$ & \\
\hline Former smoker & 479 & 7 & $14 \cdot 6$ & $1 \cdot 10(0 \cdot 52-2 \cdot 34)$ & $1 \cdot 12(0 \cdot 53-2 \cdot 38)$ & $0 \cdot 766$ \\
\hline Current smoker & 640 & 4 & $6 \cdot 25$ & $0 \cdot 51(0 \cdot 19-1 \cdot 36)$ & $0 \cdot 52(0 \cdot 19-1 \cdot 39)$ & $0 \cdot 192$ \\
\hline $1-19$ & 479 & 3 & $6 \cdot 26$ & $0 \cdot 50(0 \cdot 16-1 \cdot 56)$ & $0 \cdot 51(0 \cdot 16-1 \cdot 60)$ & $0 \cdot 250$ \\
\hline$\geqslant 20$ & 161 & 1 & $6 \cdot 21$ & $0 \cdot 52(0 \cdot 07-3 \cdot 75)$ & $0 \cdot 53(0 \cdot 07-3 \cdot 80)$ & $0 \cdot 528$ \\
\hline
\end{tabular}

* Adjusted for age, sex, family history of herpes zoster and underlying diseases.

Regarding mechanisms, the reactivation of VZV has been suggested to have a relationship with the immune system of patients. The ratio of $\mathrm{CD} 4+$ to CD8+ lymphocytes (CD4+/CD8+ ratio), a surrogate marker for cellular immunity, was $40 \%$ lower in acutephase herpes zoster patients compared to healthy persons [15], as a result of a $10 \%$ higher total of CD4+ lymphocytes and a 70\% higher total of CD8+ lymphocytes in particular. The CD4+/CD8+ ratio was $5-10 \%$ higher in smokers than in non-smokers [16, 17]. Furthermore, the CD4+/CD8+ ratio was $10 \%$ higher in light to moderate smokers (10-49 pack-years) but $20 \%$ lower in heavy smokers (50-120 pack-years) compared to that of non-smokers [18]. These findings suggest that cellular immunity may be enhanced in light to moderate smokers but reduced in heavy smokers. The lower incidence of herpes zoster associated with current smoking can be explained in part by enhanced cellular immunity. No further risk reduction of incident herpes zoster associated with increased number of cigarettes smoked may be explained by a potential deleterious effect on cellular immunity by heavy smoking.

\section{CONCLUSION}

Smoking was inversely associated with incidence, as well as past history of herpes zoster. The inverse association between smoking and risk of herpes zoster does not imply the encouragement of smoking because of its strong health hazard. Our study result, however, helps to elucidate a part of the mechanisms for the development of herpes zoster.

\section{ACKNOWLEDGEMENTS}

We express our gratitude to the following medical organizations for their cooperation: Shozu County Medical Society, Shodoshima Federation of Self-Government Bodies, Tonosho Town Autonomous Liaison Council, Shodoshima Town Government and Tonosho Town Government.

This work was part of the SHEZ Study supported by Grants-in-Aid for Scientific research from the Japanese Ministry of Health, Labour, and Welfare for Research on Publicly essential drugs and Medical devices (fiscal years 2008-2010) (KHC1102) and for Public-private Sector Joint research on Publicly Essential drugs (fiscal year 2011-2012) (KHC1102), as well as research funds from the research Foundation for Microbial diseases of Osaka University.

\section{DECLARATION OF INTEREST}

None. 


\section{REFERENCES}

1. Brisson M, et al. Epidemiology of varicella zoster virus infection in Canada and the United Kingdom. Epidemiology \& Infection 2001; 127: 305-314.

2. Gershon A, et al. Advances in the understanding of the pathogenesis and epidemiology of herpes zoster. Journal of Clinical Virology 2010; 48: S2-S7.

3. Thomas SL, et al. What does epidemiology tell us about risk factors for herpes zoster? Lancet Infectious Diseases 2004; 4: 26-33.

4. Arvin A. Aging, immunity, and the varicella-zoster virus. New England Journal of Medicine 2005; 352: 2266-2267.

5. Morgan A, et al. Herpes zoster and HIV-1 infection in a rural Ugandan cohort. AIDS 2001; 15: 223-229.

6. Hata A, et al. Risk of Herpes zoster in patients with underlying disease: a retrospective hospital-based cohort study. Infection 2011; 39: 537-544.

7. Thomas SL, et al. Contacts with varicella or with children and protection against herpes zoster in adults: a case-control study. Lancet 2002; 360: 678-682.

8. Salleras M, et al. Contacts with children and young people and adult risk of suffering herpes zoster. Vaccine 2011; 29: 7602-7605.

9. Schmader K, et al. Racial and psychosocial risk factors for herpes zoster in the elderly. Journal of Infectious Disease 1998; 178: S67-S70.
10. Irwin M, et al. Cellular immunity to varicella-zoster virus in patients with major depression. Journal of Infectious Disease 1998; 178: S104-S108.

11. Thomas SL, et al. Case-control study of the effect of mechanical trauma on the risk of herpes zoster. British Medical Journal 2004; 328: 439-440.

12. Thomas SL, et al. Micronutrient intake and the risk of herpes zoster: a case-control study. International Journal of Epidemiology 2006; 35: 307-314.

13. Takao Y, et al. Prospective cohort study of herpes zoster in Shozu county: The Shozu Herpes Zoster (SHEZ) Study. Journal of Epidemiology 2012; 22: 167-174.

14. Schmader K, et al. Race and stress in the incidence of herpes zoster in older adults. Journal of the American Geriatrics Society 1998; 46: 973-977.

15. Higa K, et al. T-lymphocyte subsets in otherwise healthy patients with herpes zoster and relationships to the duration of acute herpetic pain. Pain 1992; 51: 111-118.

16. Tollerud D, et al. The effect of cigarette smoking on $\mathrm{T}$ cell subsets. American Review of Respiratory Disease 1989; 139: 1446-1451.

17. Mili F, et al. The associations of race, cigarette smoking, and smoking cessation to measures of the immune system in middle-aged men. Clinical Immunology and Immunopathology 1991; 59: 187-200.

18. Miller LG, et al. Reversible alterations in immunoregulatory T cells in smoking: Analysis by monoclonal antibodies and flow cytometry. Chest 1982; 82: 526-529. 